\title{
The Analysis on the Effectiveness of Water Conservancy Investment in Guizhou*
}

\author{
Rong Qiu \\ Research Institute of Southwest Economic Development \\ Guizhou University of Finance and Economics \\ Guiyang, China
}

\author{
Xiao Teng \\ Guizhou University of Finance and Economics \\ Guiyang, China
}

\begin{abstract}
Guizhou is an underdeveloped district of China, and there natural disasters are very serious, which make Guizhou suffer huge economic loss every year. The natural disasters such as drought and flood, ice and snow seriously restrict the development of "agriculture, rural areas and farmers". Through the analysis on investment in agricultural water conservancy infrastructure, especially in water conservancy construction of irrigation area and on the relationship with the disasters, this paper offered new ideas for prevention and treatment of disasters.
\end{abstract}

Keywords-natural disasters; agricultural infrastructure; investment of water conservancy

\section{INTRODUCTION}

Guizhou is a multi hazard and less developed province, it's located in the eastern slope of the Yunnan- Guizhou Plateau, and it belongs to the subtropical humid monsoon climate zone, most of the area is carbonate distribution. The natural environment is of the ravines, high mountains and steep slopes, and Guizhou is the only province with no plain in China. Due to the special georaphy and meteorological characteristics as well as the economic and social development, disasters happen frequently. Natural disasters include: flood disaster (floods, in spate, water logging, etc.), drought and geological disasters (landslide, debris flow, landslide, collapse, earthquake, ground fissure, etc.), pest and rodent. In 1946, intensity of hail disasters happened in Qinglong, Anlong, Xingren, Wangmo, Hengce, in this disaster, tens of thousands of houses damaged. In 1951, counties were liable to drought, water, disease, pests; from 1959 to 1961 , three years of natural disasters resulting in disease of the dead of starvation; drought in 1963 and 1972; in 1996 and 1998, flood happened in Duyun, Guiyang, Tongren, QianDong-nan; 1994 in Guiyang and 2001 in Zunyi happened storm; In 2002, the province suffered from the autumn wind; in 2004 , Nayong suffered serious mountain landslide. ${ }^{1}$ The flood disaster occurred in Shiqian County, killing more than 150 thousand people were affected.

*This paper is one of the results of research project of Guizhou Provincial Education Department Base of Humanities and social science in 2014. The Base name: "Chinese Western Modernization Development Research Center in Guizhou University of Finance and Economics".Name of the project: "Research on the development of agricultural modernization and informatization in Guizhou ". Number of the project : JD2014112.

${ }^{1}$ Data sources: Guizhou Civil Affairs Bureau website
Especially the geological disasters occurred with high frequency. In May 2010, nine city (state, land) and 85 counties (cities, districts) of 88 county (city, district) in Guizhou Province suffered varying degrees of drought; with a total population of 1868. 9 million people were affected and 163. 9 million hectares of crops affected area, tolls caused direct economic losses of 132.3 billion. In 2011, Guizhou suffered rare drought, again, according to relevant statistics, In September Guizhou province's 88 counties (cities, districts) were affected to varying degrees, of which 31 counties are special drought and 39 counties are severe drought. In June, Wangmo, in South of Guizhou Province, suffered torrential disaster of flood, 13. 94 million people were affected and 11800 hectares of crops affected, 801 families collapsed and 2403 houses. The disasters caused direct economic losses reached 1.71 billion.

These natural disasters caused huge losses to the local government and the masses of the people. Many natural disasters bring people's trauma. Speaking of microscopic, natural disasters, especially sudden natural disasters will cause panic, anxiety, depression and other emotional and perceptual problems. These make people lose their home, property or even life. To macro terms, the natural disasters will cause serious economics damage, and make local economic stagnation or even retrogression. Some rural areas which are originally undeveloped may be of more barren land, less food. The natural disasters will restrict the agricultural development, resulting in local people's life more poverty. Natural disasters seriously affect the region's economic development and social stability. Continuous natural disasters will cause chaos of the social order, once the disaster occurs material fed, it will cause panic, resulting in looting supplies. If the plague caused by the disaster, it may lead to social unrest or even political instability.

\section{THE INTRODUCTION OF WATER CONSERVANCY IN GUIZHOU}

Agriculture is the foundation of rural economy, water is the lifeblood of agriculture. Guizhou Province is rich in resources. Yangtze River and Pearl River Basin run through Guizhou. Rivers such as Chishui River and Nanpanjiang nourished this piece of land. According to thestatistics, by 2010, Guizhou Province already has 9 large reservoirs in block, which is famous for Nanpan River downstream -a large (a) reservoir, Wanfeng reservoir; Medium-sized 
reservoirs are more than 30 sit, such as a medium-sized reservoirs in the Nanpanjiang River downstream, Basuo reservoir; In addition, Guizhou has small (a) reservoir more than 400, small (b) reservoir more than 1500 sit. The Guizhou province water conservancy facilities are very rich.

According to statistics, the effective irrigation area of Guizhou Province is 1317.59 thousand hectares, watersaving irrigation area is 403.28 thousand hectares, the area of water logging is 55.70 thousand hectares, the soil erosion area of governance is 322.5 thousand hectares. ${ }^{2}$ As we can see, although soil erosion is more because of natural disasters, however, the effect of continuous treatment is very obvious.

\section{THE ANALYSIS ON CORRELATION BETWEEN INVESTMENT OF W ATER CONSERVANCY AND IRRIGATION AREA OF CROPS}

\section{A. General Situation of Water Conservancy Investment}

In response to the central document, emphasizing the focus on water conservancy infrastructure construction, Guizhou Province increased the investment of water conservancy infrastructure in recent years, as shown in "Fig. 1 ".

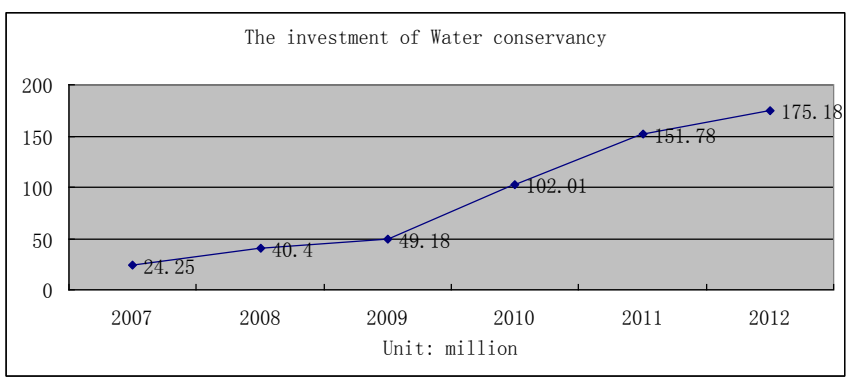

Fig. 1. The investment Guizhou water conservancy during 2007 to 2012

As you can see, the investment in water conservancy is not only increases rapidly in quantity, and the growth rate is also rising ceaselessly. The water conservancy investment approximately in 2012 is 8 times as much in 2007. In particular, droughts and floods is outbreak in 2008, the input of water conservancy increased sharply, from 2008 to 2009 , the investment of water conservancy increase rate was $21.7 \%$; from 2009 to 2010, the investment of increase water conservancy rate reached $107.4 \%$, it can be described as rapid growth.

In order to directly observe the proportion of the input of water conservancy account for the whole financial expenditure of Guizhou Province, we drew the following pie chart "Fig. 2".

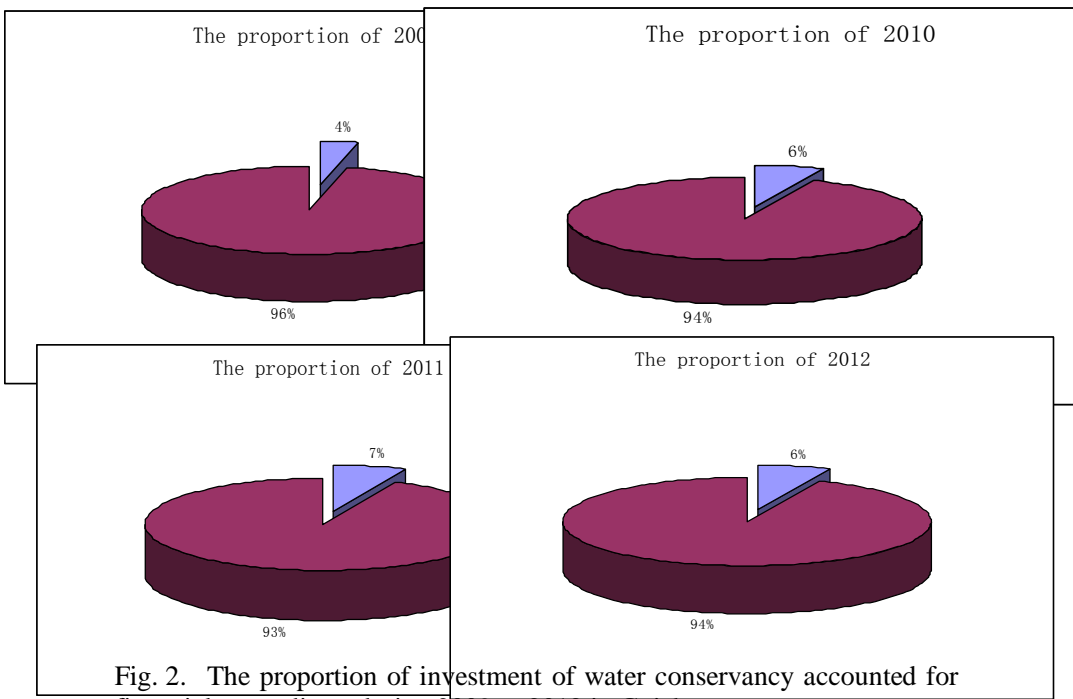

financial expenditure during 2009 to 2012 in Guizhou

The increase of the proportion of investment of water conservancy accounted for financial expenditure in Guizhou is slowly, but the proportion increases greatly. However, as the base, the fiscal expenditure is of great value and growing very fast, so the input of water conservancy is significantly increased in quantity. It can be seen that the fiscal expenditure is significantly accelerate in Guizhou in recent years. In addition, the investment of other inputs is also increasing.

\section{B. Correlation Analysis of Water Conservancy Investment and Effective Irrigation Area}

An important objective of construction of rural water conservancy infrastructure is to improve the irrigation fields, fight against drought and flood and ensure agricultural production "Table I". 
TABLE I. STATISTICS OF 2007-2012 INVESTMENT OF WATER CONSERVANCY AND IRRIGATION AREA IN GUIZHOU

\begin{tabular}{|c|l|l|l|l|l|l|}
\hline Project & \multicolumn{1}{|c|}{$\mathbf{2 0 0 7}$} & \multicolumn{1}{|c|}{$\mathbf{2 0 0 8}$} & \multicolumn{1}{|c|}{$\mathbf{2 0 0 9}$} & \multicolumn{1}{|c|}{$\mathbf{2 0 1 0}$} & \multicolumn{1}{|c|}{$\mathbf{2 0 1 1}$} & \multicolumn{1}{|c|}{10} \\
\hline The investment of water conservancy & 24.25 & 40.40 & 49.18 & 102.01 & 151.78 & 175.18 \\
\hline The effective irrigation area & 894.28 & 987.41 & 1087.41 & 1195.33 & 1266.80 \\
\hline
\end{tabular}

We defined the water investment of water conservancy as IWC, and the effective irrigation area as EIA. Correlation analysis was done between the two variables, and we establish the following model.

\section{$\mathrm{EIA}=\beta_{1}+\beta_{2} \mathrm{IWC}+\mu$}

The analysis result is follows "Fig. 3".

\begin{tabular}{|c|c|c|c|c|}
\hline \multicolumn{5}{|c|}{$\begin{array}{l}\text { Dependent Variable: EIA } \\
\text { Method: Least Squares } \\
\text { Date: } 11 / 16 / 14 \text { Time: } 21: 14 \\
\text { Sample: } 20072012 \\
\text { Included observations: } 6\end{array}$} \\
\hline Variable & Coefficient & Std. Error & t-Statistic & Prob. \\
\hline INC & 2.525910 & 0.376994 & 6.700141 & 0.0026 \\
\hline c & 895.9593 & 40.36066 & 22.19883 & 0.0000 \\
\hline R-squared & 0.918187 & \multirow{7}{*}{\multicolumn{2}{|c|}{$\begin{array}{l}\text { Mean dependent var } \\
\text { S.D. dependent var } \\
\text { Akaike info criterion } \\
\text { Schwarz criterion } \\
\text { Hannan-Quinn criter. } \\
\text { Durbin-watson stat }\end{array}$}} & 1124.470 \\
\hline Adjusted R-squared & 0.897734 & & & 165.3151 \\
\hline S.E of regression & 52.86632 & & & 11.03461 \\
\hline Sum squared resid & 11179.39 & & & 10.96520 \\
\hline Log likelihood & -31.10383 & & & 10.75674 \\
\hline F-statistic & 44.89189 & & & 1.133506 \\
\hline Prob(F-statistic) & 0.002582 & & & \\
\hline
\end{tabular}

Fig. 3. The analysis result of IWC

From the figure of the results, we can see that the goodness of fit value is 0.918187 , close to 1 , it fits better. The $\mathrm{P}$ values were less than 0.05 ; the regression equation can be obtained.

\section{$\mathrm{EIA}=895.9593+2.52591 \mathrm{IWC}$}

The related analysis shows that the investment of water conservancy is related to the effective irrigation area. That is to say, increase the construction of water conservancy infrastructure can help the development of agricultural production. Although during natural disasters occur, the water conservancy construction can reduce disaster economic loss to a certain extent. Separate the results from the analysis of investment of water conservancy; the investment of agricultural water conservancy infrastructure has the profound influence on farmland irrigation. That is to say, agricultural water conservancy infrastructure can resist the effects of natural disasters such as flood and drought. But the result of correlation between natural disasters and rural infrastructure construction is not as good as expected, it needs to collect more data and make more in-depth study.

\section{ANALYSIS ON THE CAUSES OF THE SHORTAGE OF AGRICULTURAL INFRASTRUCTURE INVESTMENT}

\section{A. The Characteristics of Agricultural Infrastructure's Public Goods under the Contract Responsibility System}

In the era of planned economy, the agricultural infrastructure mainly relied on the government's investment. The village collective organization was responsible for organizing the famers to construct and maintain. They have specific responsibility subject and direct beneficiaries. But under the Household Contract Responsibility System, the rural household managed the lands dispersedly. The characteristics of public goods were gradually highlighted by the agricultural infrastructure, such as the non-separable utility, the non-competitive in consuming and non-exclusive in profiting. For the villages outside the region, the agricultural infrastructure is quasi-public goods. But for the family farmers within the region, it has the characteristic of purely public goods. So there was no intention for individual farmer family to input. Because of the agriculture-tax exemption, the revenue originally attached to the agricultural tax will disappear. It means that the village collective organization lost their source of income and the independent financial right. Naturally, they didn't have the ability and motive of constructing and maintaining the agricultural infrastructure. A survey found that most of the agricultural infrastructure displays the typical features --- "tragedy of the commons". Especially the farmland gully is blocked and the facilities of irrigation works wear out seriously.

\section{B. Analysis of the Investment Subject}

The nature of agricultural infrastructure determines that the government should play a major role in investing the construction of agricultural infrastructure. It is very difficult to solve the problems of the construction of agricultural infrastructure only rely on individual or collective strength. In order to clarify the action that the subject of investment may take, we should analyze the interests of various actors and their goals even the best chance for action.

In 2012, Guizhou's forestry and water conservancy investment in the classification of public expenditure in the proportion was shown below "Fig. 4". 


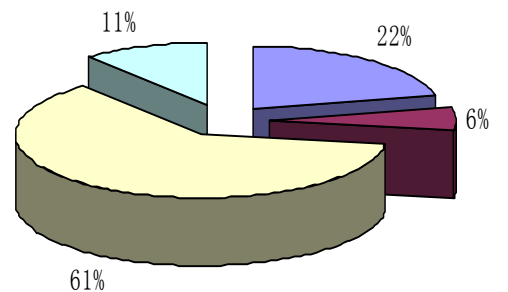

$\square$ Provincial Level
Prefecture Level
$\square$ County Leve
$\square$ Township Level

Fig. 4. Agriculture, forestry and water conservancy in 2012 accounts for grading the proportion of fiscal expenditure in Guizhou

Guizhou Province has been dominated by the local government for a long period of time. It mainly relied on the County Level's Government. In 2012, the expenditure on forestry and water conservancy investment in Guizhou Province is 275.568 billion. Of those, the county finance expenditure reached 160.145 billion, which accounts for nearly $61 \%$ of the proportion. The reason for this is that the central government concentrated on the building. So the public resources and funds must be utilized through various filtrations. In that case, the cost of infrastructure construction will increase. And there exists a short time lag. So the efficiency can't reach the highest. But the local government has a very good understanding of the local situation. It has a more accurate assessment of construction projects. As a result, the various filtrations have excluded. So they can get a more reasonable control of all kinds of resources and funds. Especially in Guizhou such an underdeveloped area, the geographical environment and the resources endowment are very different. The County Level's Government has a thorough understanding of the local situation. Therefore, to match the Prefecture-level City Government and Provincial Government, and with the help of Rural Commune-level Government, the County Level's Government can be able to complete the allocation of resources more reasonably and efficiently. Especially complete the construction and management of rural infrastructure. In addition, for the area between the County-Level Area, the agricultural infrastructure is quasi-public goods, even private goods. Therefore, the County Level's Government is an important subject of spending for the jurisdiction area's the agricultural infrastructure. But the revenue of the County Level's Government did not reflect directly. It fulfils its responsibilities passively. It has something to do with punishment instead of encouragement. And the punishment is about non-economic factors.

\section{CONCLUSION}

In fact, the County Level's Government has limited room for man oeuvre. Especially in some remote county, fiscal revenue is very poor, sometimes can't make ends meet. Even appears "ate meal the finance". That's just a drop in the bucket to meet the needs of Demand for Agricultural Infrastructure. Moreover, the more impoverished the areas are, the more disaster prone will happen. And the poverty and disaster will cause a vicious cycle. This requires other inputs of the main county government outside the provincial and local government in the financing plan, increasing investment in agricultural infrastructure. In this way, the disaster will be prevented and reduced.

\section{REFERENCES}

[1] Liang Xiaowei. Looked from the drought in southwest China, the construction of agricultural water conservancy infrastructure is urgent. The Economic Herald, 2010(04):11-12.

[2] Gan Lin. The preference of water conservancy infrastructure status and financing mode of rural reform [J]., 2009 (7): 125-130.

[3] Liu Yanping. Study on the realistic characteristics of [J]. agricultural functions of local government in the construction of agricultural infrastructure, 2009 (10): 234-236.

[4] The central document stressed the focus on water conservancy infrastructure construction. The Water Conservancy of China, 2010 (02).

[5] The characteristics of geological disaster and its prevention in Guizhou Province. Guizhou Department of land and resources department website, 2010

[6] Li Zhanshu. Speeding up the reform and development of the realization of water conservancy of.2010 in Guizhou Province, the province's water conservancy work conference, Guizhou water resources department website. 